\title{
In silico Characterization of Rad51a Interactions with Cancer- Related Proteins
}

\author{
Kleber Santiago Freitas e Silva* \\ Biological Sciences Institute, Federal University of Goiás, Brazil
}

*Corresponding author: Kleber Santiago Freitas e Silva, Biological Sciences Institute, Federal University of Goiás, Brazil, Tel (Fax): 5562-32820744

\begin{abstract}
RAD51a is a highly conserved protein and its major role is the repair of DNA double strand breaks. Endogenous species are generated during normal cell metabolic activities and can cause damage to DNA, as well as several environmental factors. The interactions RAD51a perform with other proteins help the maintenance of oncogenetic metabolism within cells. RAD51a interacts with PCNA, FANCD2 and $A B L 1$, among many other cancer-related proteins. PCNA acts as a DNA clamp and is related to the replication process, FANCD2 arrests DNA replication fork progression in response to DNA damage and $A B L 1$ is a proto-oncogene related to cell differentiation. Protein-protein interactions (PPIs) are governed by the presence of hot spots within the interface of interaction. Identifying residues directly involved in PPIs enables the likelihood of modulating such complexes with biologically active small molecules such as synthetic peptides, which leads to a new era of diseases treatment. Here, we use an in silico approach to determine the best free-energy of interaction between RAD51a and the targeted cancer-related proteins PCNA, FANCD2 and two chains of $A B L 1$. We propose an interaction interface between RA$\mathrm{D} 51 \mathrm{a}$ and those proteins and identified hot spots that could be useful to understand the molecular basis of their interaction. We believe that further studies may find small-targeted molecules with therapeutics properties that could modulate those interactions and increase our knowledge regarding the complex trait diseases such as cancer.
\end{abstract}

\section{Keywords}

RAD51a, PCNA, FANCD2, ABL1, Protein-protein interactions

\section{Introduction}

RAD51a is a highly conserved protein and its major role is the repair of DNA double strand breaks (DSBs) [1]. Genome integrity is maintained by a series of met- abolic events in which cells recognize and amend DNA molecules that is damaged due to either endogenous or exogenous agents [2,3]. Endogenous reactive oxygen species (ROS) are generated during normal cell metabolic activities [4] and exogenous damage can be caused by radiation $[5,6]$, chemicals $[7,8]$ and other environmental factors $[9,10]$. DNA damage leads to a structural impairment of the double helix molecule [11] and consequently affects the ability of the cell to translate the information encoded within genetic material. In addition, DNA damage can lead to mutations in the genome and alter the survivability rate of daughter cells during cell division [12].

RAD51a takes part in DNA repair through homologous recombination. The protein contains 339 amino acids and folds into a heptameric structure formed by identical polypeptide chains (Figure $1 A$ ). The 3-D (three-dimensional) structure of RAD51a is related to its DNA repair function. When a DNA DSB takes place, RAD51a searches for homology and catalyzes strand pairing in order to repair the damage. The RAD51a structure establishes a helical nucleoprotein filament around the DNA [13] can bind to other proteins to accomplish its function $[14,15]$. RAD51a interacts with proteins related to the DNA metabolism, such as the FA Complementation Group D (FANCD2), the proliferating cell nuclear antigen (PCNA) $[16,17]$ and the Abelson murine leukemia viral oncogene homolog 1 (ABL1) [18-20]. All of them are somehow related to the metabolism of DNA and anomalies within their sequence or disruption of the interactions they perform with other proteins may increase cancer and other diseases sus-

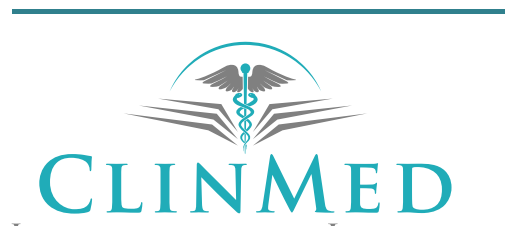

INTERNATIONAL LIBRARY
Citation: e Silva KSF (2019) In silico Characterization of Rad51a Interactions with Cancer-Related Proteins. J Genet Genome Res 5:045. doi.org/10.23937/2378-3648/1410045

Accepted: June 26, 2019: Published: June 28, 2019

Copyright: (c) 2019 e Silva KSF. This is an open-access article distributed under the terms of the Creative Commons Attribution License, which permits unrestricted use, distribution, and reproduction in any medium, provided the original author and source are credited. 

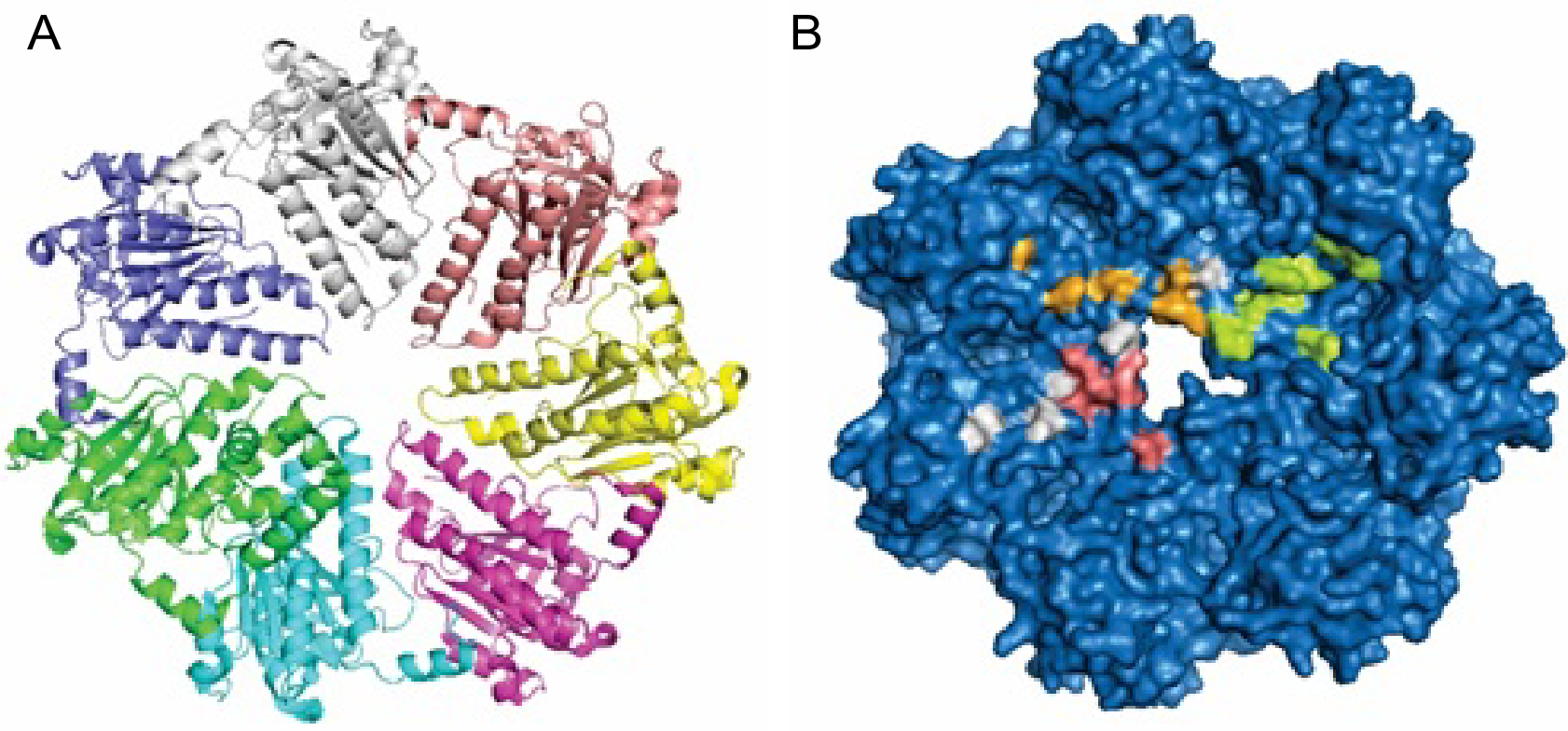

Figure 1: RAD51a 3-D structure. A - The heptameric structure of RAD51a. Each color represents an identical polypeptide chain of the protein. B - 3-D structure showing the surface of RAD1a and the predicted hot spots for its interaction with the PCNA (orange), FANCD2 (white), SH3 domain (pink) and tyrosine kinase domain (green) of ABL1.

ceptibility.

Cancer is a prevalent disease worldwide. Over 90.5 million people had cancer in 2015 [21]. It is estimated that over 14.1 million new cases of cancer occur every year, leading to 8.8 million deaths [22]. RAD51a, PCNA, FANCD2 and ABL1 are potential therapeutic targets in cancer therapy [23-26] as they are related to several types of cancer. PCNA acts as a DNA clamp and is related to the replication process, FANCD2 arrests DNA replication fork progression in response to DNA damage and ABL1 is a proto-oncogene related to cell differentiation. These proteins interact with a variety of molecules in order to maintain genomic stability. Protein-protein interactions (PPIs) are a key factor for a proper DNA metabolism and they regulate a wide range of biochemical pathways and processes, including homologous recombination [27], cell division, cell cycle progression [28] and cancer onset [29].

PPIs help to understand how proteins contribute to dysregulated oncogenic pathways and disease progression. Moreover, several PPIs related to nuclear metabolism show therapeutic relevance, mainly regarding cancer, and have been targeted by high-throughput approaches in order to generate new insights on the increasing biological data [30]. Experimental and in silico approaches related to protein networks have contributed to the genetic and molecular classification of the most prevalent cancers in humans [31]. In addition, cancer-related proteins are therapeutically targeted through the inhibition of their molecular interactions. Therefore, the study of disease-specific protein interaction network is vital to direct cancer treatment [31,32].

Here, we use an in silico approach to determine the best free-energy of interaction between RAD51a and the targeted cancer-related proteins PCNA, FANCD2 and two chains of $A B L 1$. We propose an interaction interface between RAD51a and those proteins and identified hots pots that could be useful to understand the molecular basis of their interaction.

\section{Materials and Methods}

All the 3-D structures used in the analysis are available in the PDB (protein databank; https://www.rcsb. org/). We used KBDOCK in order to find protein domains and possible interaction between protein domains [33]. The protein docking was performed by ClusPro [34]. We used PyMol (https://pymol.org) for the visualization of the interface of interaction and the visualization of hot spots and polymorphic residues. The hot spots in the proteins under study were identified by KFC2. The server offers an automated analysis of a protein complex interface. The server analyses the structural environment around amino acid residues and checks for already known hot spots environments determined experimentally. The hot spot prediction is based on characteristics regarding conformation specificity (K-FADE) and biochemical features such as hydrophobicity (K-CON) $[35,36]$. Finally, the polymorphic residues were identified through the dbSNP (data base of single nucleotide polymorphism; https://www.ncbi. nIm.nih.gov/SNP).

\section{Results and Discussion}

\section{Identification of hot spots on RAD51a structure}

PPIs are governed by hot spots that are present on the interface of interaction. Hot spots are amino acid residues that account to the binding free energy of a 
Table 1: Cluster of hot spot residues on RAD51a interface of interaction.

\begin{tabular}{|c|c|c|c|c|}
\hline Chain & Residue & KFC2-A* & KFC2-B ${ }^{* *}$ & Partner \\
\hline$A$ & ARG 251 & 0.97 & 0.16 & PCN \\
\hline$F$ & PHE 137 & 0.38 & 0.18 & PCN \\
\hline$F$ & GLN 258 & 0.39 & 0.04 & PCN \\
\hline$F$ & HIS 303 & 1.56 & 0.10 & PCN \\
\hline $\mathrm{G}$ & ILE 249 & 1.10 & 0.17 & PCN \\
\hline G & ARG 251 & 0.73 & 0.09 & PCN \\
\hline G & LEU 254 & 0.28 & 0.04 & PCN \\
\hline A & ILE 249 & 1.45 & 0.20 & FANCD2 \\
\hline A & ARG 251 & 1.68 & 0.28 & FANCD2 \\
\hline$E$ & PHE 137 & 1.27 & 0.34 & FANCD2 \\
\hline$E$ & ARG 251 & 0.93 & 0.10 & FANCD2 \\
\hline$E$ & LEU 254 & 0.40 & 0.07 & FANCD2 \\
\hline$E$ & GLN 258 & 0.69 & 0.06 & FANCD2 \\
\hline$E$ & HIS 303 & 1.25 & 0.01 & FANCD2 \\
\hline$E$ & ILE 304 & 0.39 & 0.11 & FANCD2 \\
\hline$E$ & TYR 314 & 1.25 & 0.30 & FANCD2 \\
\hline $\mathrm{F}$ & ILE 249 & 1.14 & 0.15 & FANCD2 \\
\hline $\mathrm{F}$ & ARG 251 & 1.31 & 0.20 & FANCD2 \\
\hline$D$ & LEU 254 & 0.97 & 0.13 & ABL1-SH3 \\
\hline$E$ & ARG 251 & 1.79 & 0.33 & ABL1-SH3 \\
\hline$E$ & LEU 254 & 1.44 & 0.31 & ABL1-SH3 \\
\hline$E$ & ARG 257 & 0.53 & 0.25 & ABL1-SH3 \\
\hline $\mathrm{F}$ & ILE 249 & 1.34 & 0.26 & ABL1-SH3 \\
\hline A & PHE 137 & 1.44 & 0.39 & ABL1-TK \\
\hline A & ARG 251 & 1.20 & 0.23 & ABL1-TK \\
\hline$A$ & LEU 254 & 1.04 & 0.24 & ABL1-TK \\
\hline$A$ & ARG 257 & 0.17 & 0.11 & ABL1-TK \\
\hline A & GLN 258 & 0.66 & 0.15 & ABL1-TK \\
\hline A & HIS 303 & 1.92 & 0.33 & ABL1-TK \\
\hline$A$ & ILE 304 & 0.73 & 0.20 & ABL1-TK \\
\hline$A$ & LEU 305 & 1.39 & 0.27 & ABL1-TK \\
\hline$A$ & ILE 328 & 0.91 & 0.05 & ABL1-TK \\
\hline$B$ & ARG 245 & 0.81 & 0.05 & ABL1-TK \\
\hline
\end{tabular}

*Hot spot model based on shape specificity features; " model based on biochemical features such as intermolecular hydrogen bonds.

certain protein $[35,36]$ and is the site that has a higher probability for ligands to interact $[37,38]$. Analyzing the interaction interface between RAD51a and its binding partners, we identified several clusters of hot spots (Table 1 and Figure 1B). Identifying residues directly involved in PPIs enables the likelihood of modulating such complexes with biologically active small molecules such as synthetic peptides [39]. Moreover, the development of such techniques is promising for the therapeutics of complex diseases like cancer [40-44], Alzheimer's disease [45], Parkinson's disease [46], epilepsy [47] and infection [48].

Hot spots govern thermodynamic processes relat-
Table 2: Cluster of hot spot residues on PCNA interface of interaction.

\begin{tabular}{|l|l|l|l|l|}
\hline Chain & Residue & KFC2-A $^{*}$ & KFC2-B $^{* *}$ & Partner \\
\hline d & TYR 151\# & 0.35 & 0.11 & RAD51a \\
\hline d & HIS 152 & 1.70 & 0.15 & RAD51a \\
\hline d & LYS 154 & 1.73 & 0.14 & RAD51a \\
\hline d & ARG 156 & 1.49 & 0.34 & RAD51a \\
\hline d & LEU 157 & 1.42 & 0.09 & RAD51a \\
\hline d & ILE 158 & 1.32 & 0.29 & RAD51a \\
\hline d & PHE 159 & 1.12 & 0.12 & RAD51a \\
\hline
\end{tabular}

"Hot spot model based on shape specificity features; " Hot spot model based on biochemical features such as intermolecular hydrogen bonds; "Polymorphic residues that may greatly affect the free energy binding of PCNA to RAD51a.

ed to PPIs. The amino acid residues identified as hot spots on the RAD51a interaction interfaces define the biochemical properties involved in its interactions with PCNA, FANCFD2 and ALB1 (Figure 1B). Solvation potential, residue interface propensity, hydrophobicity, planarity, protrusion and accessible surface area regulate those interactions and guarantee or not the functions those proteins exert in the complex.

\section{In silico model for the RAD51a interaction with PCNA}

PCNA is highly conserved among species and required for a proper DNA replication [49]. This protein surrounds the DNA and recruit partner proteins related to DNA metabolism such as replicatio [50], repair [50,51], chromatin remodeling [52] and epigenetics [53]. PCNA has 261 amino acid residues and 3 identical units of a polypeptide (Figure 2A), organized in a way that facilitates it to encircle the DNA when PCNA is active.

The interfaces of PPIs are normally large and with no empty spaces or pockets (Figure 2B) compared to binding sites for small molecules $[54,55]$. Conserved amino acid residues, the so-called hot spots, stabilize the RAD51a-PCNA complex (Table 2; Figure 2C) and this interaction guarantees a high-fidelity repair of DSBs on the DNA. DNA repair is essential to recover genetic information that would be possibly lost during natural processes that induce DBSs, such as replication and homologous recombination. Figure $2 B$ shows a model for the interaction between RAD51a and PCNA. It has been suggested that the interaction between these two proteins are regulatory, and RAD51a inhibits PCNA in order to arrest the replication process [56-58].

Disruption of the thermodynamic balance within the RAD51a-PCNA complex may be a cause for disease onset. Mutations and polymorphisms in either proteins could affect the free-energy pattern maintained by hot spots in the interaction interface and induce cancer development. More drastic consequences would be seen if the conserved amino acid residues (Table 3) are af- 

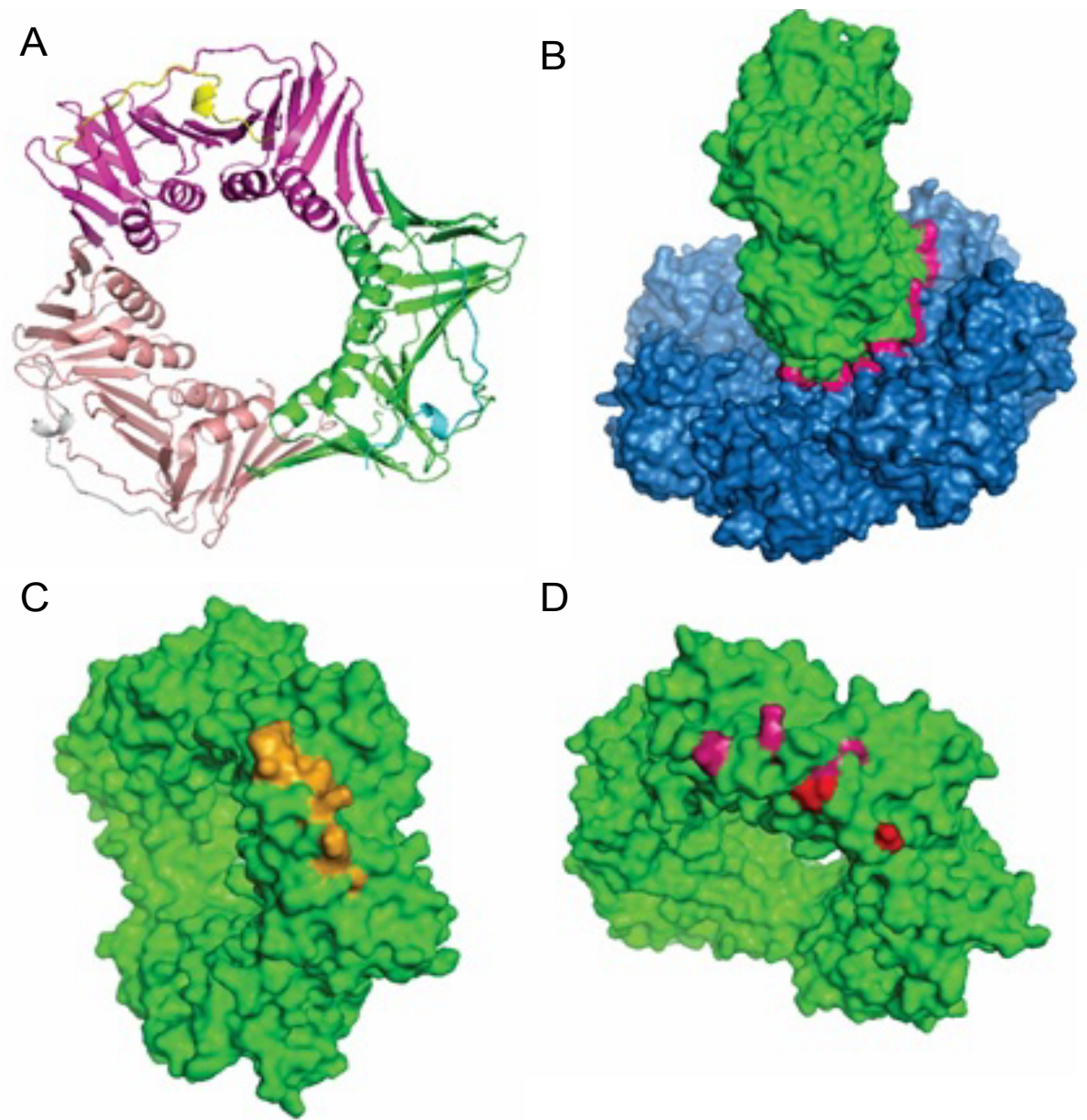

D

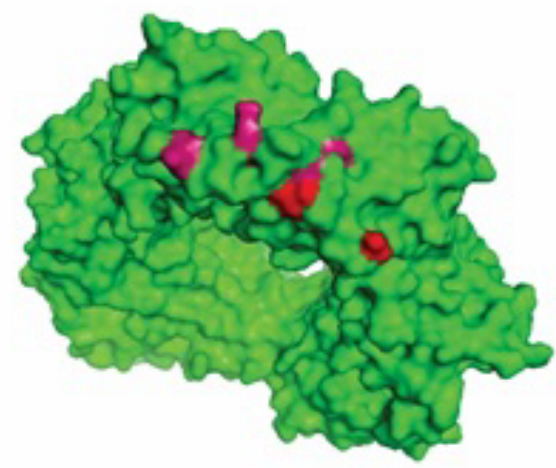

Figure 2: Interaction between RAD51a and PCNA. A - 3-D structure of PCNA. PCNA is a protein trimer, each chain is representing by a different color. B - The interface of interaction between RAD51a (blue) and PCNA (green). The interface of interaction in the contact region between the interacting proteins (pink), which is characterized by a large region without empty spaces or pockets. C - The figure represents in orange the predicted hot spots on the PCNA protein (green) when it interacts with RAD51a. D - The figure shows highly polymorphic residues that overlaps hot spots (pink) or are present in the proximity of hot spots (red).

Table 3: Cluster of hot spot residues on FANCD2 interface of interaction.

\begin{tabular}{|l|l|l|l|l|}
\hline Chain & Residue & KFC2-A $^{*}$ & KFC2-B $^{* *}$ & Partner \\
\hline a & ARG 591 & 0.25 & 0.30 & RAD51a \\
\hline a & HIS 594\# & 0.96 & 0.24 & RAD51a \\
\hline a & GLN 597 & 0.56 & 0.02 & RAD51a \\
\hline a & ARG 648 & 0.82 & 0.10 & RAD51a \\
\hline a & ILE 849\# & 0.32 & 0.05 & RAD51a \\
\hline a & ILE 855\# & 0.64 & 0.16 & RAD51a \\
\hline a & ARG 879\# & 1.12 & 0.34 & RAD51a \\
\hline a & ARG 886 & 0.74 & 0.32 & RAD51a \\
\hline a & LEU 889 & 1.74 & 0.31 & RAD51a \\
\hline
\end{tabular}

"Hot spot model based on shape specificity features; ${ }^{*}$ Hot spot model based on biochemical features such as intermolecular hydrogen bonds; "Polymorphic residues that may greatly affect the free energy binding of FANCD2 to RAD51a.

fected. Figure 2D shows some commons single nucleotide polymorphisms (SNPs) that take place on PCNA residues. We identified 7 hot spot residues on the PCNA interface of interaction with RAD51a and among them, TYR 151, LYS 154, LEU 157 are highly polymorphic. Fig- ure 2D also shows a couple of polymorphic residues that are not classified as hot spots but are in the proximity and may affect the free energy of PCNA binding to RAD51a. SNPS in such residues may regulate PNCA interaction with other proteins and its expression. PNCA polymorphisms have been found in patients with several types of cancer $[59,60]$.

\section{In silico model for the RAD51a interaction with FANCD2}

The protein FANCD2 is ubiquitinated as a response to DNA damage, which is fundamental for the DNA repair. FANCD2 activity drives the homology-directed DNA repair process [61]. The result of its expression is arrest of DNA replication fork progression, protects cells from chromosome abnormalities and loss of genetic information during cell division and gamete formation [62]. The protein folds into a 3-D structure with more than $50 \%$ of helical chains (Figure 3A). The FANC protein family include several representatives with several isoforms and low levels of similarity due to the diversity of functions they present [63]. 
A

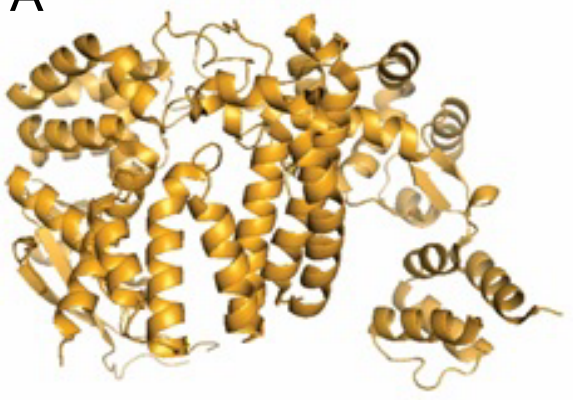

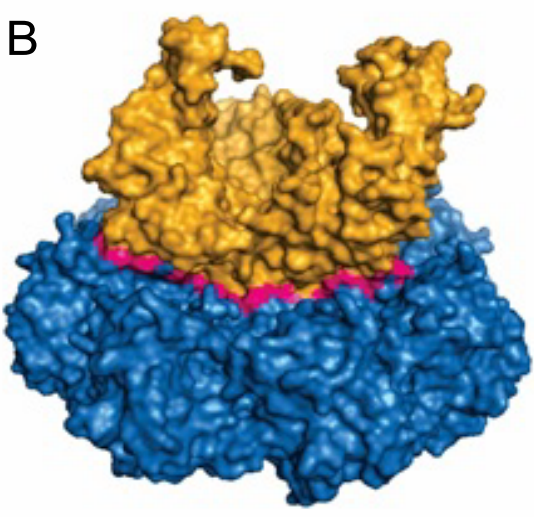

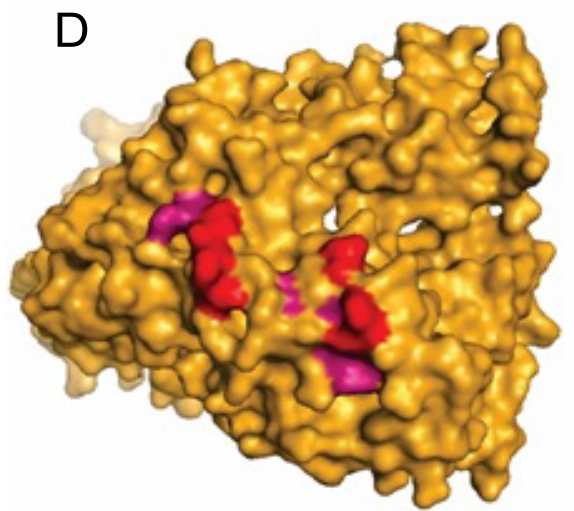

Figure 3: Interaction between RAD51a and FANCD2. A - 3-D structure of FANCD2. B - The interface of interaction (pink) between RAD51a (blue) and FANCD2 (orange). C - The figure represents in pink the predicted hot spots on the FANCD2 protein (orange) when it interacts with RAD51a. D - The figure shows highly polymorphic residues that overlaps hot spots (pink) or are present in the proximity of hot spots (red).

Figure $3 B$ shows the interface of interaction between RAD51a and FANCD2. FANCD2 is known to stabilize the complex formed by RAD51 and DNA. The protein binds to RAD51 in a way that it protects the 5 '-DNA end [17]. Patients with a disrupted structure of FANCD2, mainly carriers of Fanconi anemia, have higher risk of cancer development $[64,65]$. The most frequent cancer types related to FANCD2 are ovarian [66], hepatic [67], lung [68], breast cancer [69] and leukemia [70]. FANCD2 co-localizes with RAD51a following DNA damage is an indication that FANCD2 and RAD51a share roles in DNA repair through physical interactions $[16,17,71]$.

We found 9 conserved hot spot residues (Figure 3C) within the interaction interface of FANCD2 and RAD51a (Table 3). Among those, 5 have been identified as polymorphic residues as HIS 594 can be changed into Gly, ILE 855 into Val, ARG 879 into Lys, ARG 886 into Pro and finally ILE 849 which corresponds to a synonymous mutation (Figure 3D). Polymorphisms and mutations in FANCD2 genes have been reported to be related to cancer and other diseases [72-75].

\section{In silico model for the RAD51a interaction with two domains of ALB1}

The ABL1 protein has two main domains, a tyrosine kinase domain and a SH3 domain. The former has reg- ulatory functions to other proteins [76], is related to division, proliferation, apoptosis and differentiation [77] while the latter regulates ABL1 expression and protein-protein interactions [78]. The $\mathrm{SH} 3$ domain folds into a highly conserved 3-D structure (Figure 4A) arranged in $\beta$-strands and anti-parallel $\beta$ sheets chains [79]. The SH3 domain contains conserved aromatic amino acid that build up a hydrophobic center and an aliphatic pocket on the surface of the protein. These features are important for a correct folding of the protein and for the free-energy binding patter of ABL1 [80]. ABL1 is characterized as proto-oncogene and disruption of $\mathrm{SH} 3$ domain turns the protein into an oncogene related to onset of several type of cancers [25]. The tyrosine kinase domain of ABL1 is also highly conserved across species [81] and a large variety of kinase inhibitors have been proposed for the treatment of genetic-related anomalies [82]. Some common patterns in the protein kinase domain are recognized in several proteins, such as an ATP binding region, conserved residues, a catalytic site and peptide sequences [83]. The 3-D structure for the $A B L 1$ tyrosine kinase is represented in Figure 4B.

Both the $\mathrm{SH} 3$ and the tyrosine kinase domains of the protein ABL1 interacts with RAD51a and the interactions are related to DNA repair $[20,84]$. Interestingly, RAD51a also contains the SH3 and the tyrosine kinase domains. The interface of interaction between RAD51a 

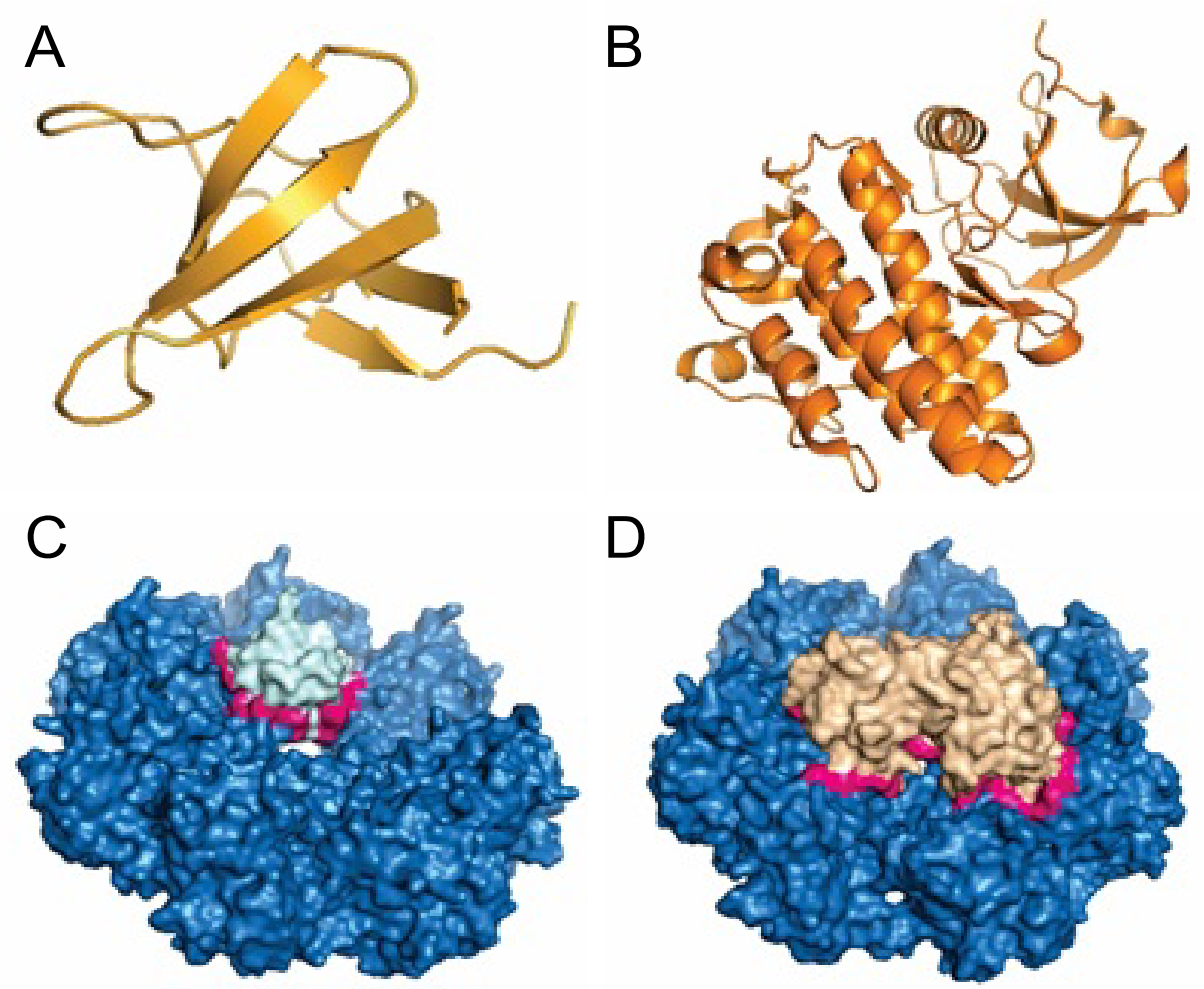

Figure 4: Interaction between RAD51a and ABL1. A - 3-D structure of ABL1 SH3 domain. B - 3-D structure of ABL1 tyrosine kinase domain. $\mathrm{C}$ - The interface of interaction (pink) between RAD51a (dark blue) and ABL1 SH3 domain (light blue). D - The interface of interaction (pink) between RAD51a (dark) and ABL1 SH3 domain (light brown).

Table 4: Cluster of hot spot residues on ABL1 interface of interaction.

\begin{tabular}{|c|c|c|c|c|}
\hline Chain & Residue & KFC2-A* & KFC2-B ${ }^{\star *}$ & Partner \\
\hline \multicolumn{5}{|c|}{ SH3 domain } \\
\hline a & PHE 72 & 0.31 & 0.31 & RAD51a \\
\hline a & GLU 98 & 1.37 & 0.07 & RAD51a \\
\hline a & TRP 99 & 1.63 & 0.31 & RAD51a \\
\hline a & TRP 110 & 0.92 & 0.29 & RAD51a \\
\hline \multicolumn{5}{|c|}{ Tyrosine kinase domain } \\
\hline a & LEU 327 & 0.34 & 0.32 & RAD51a \\
\hline a & ARG 328 & 0.25 & 0.07 & RAD51a \\
\hline a & TRP 430 & 1.34 & 0.20 & RAD51a \\
\hline a & TYR 435 & 0.49 & 0.26 & RAD51a \\
\hline a & MET 437\# & 1.15 & 0.15 & RAD51a \\
\hline a & ILE 443\# & 1.20 & 0.19 & RAD51a \\
\hline a & LEU 451\# & 1.34 & 0.33 & RAD51a \\
\hline$a$ & TYR 456\# & 1.77 & 0.38 & RAD51a \\
\hline a & MET 458 & 0.81 & 0.14 & RAD51a \\
\hline a & GLU 459 & 1.33 & 0.14 & RAD51a \\
\hline
\end{tabular}

"Hot spot model based on shape specificity features; " ${ }^{*}$ Hot spot model based on biochemical features such as intermolecular hydrogen bonds; "Polymorphic residues that may greatly affect the free energy binding of FANCD2 to RAD51a.

and ABL1 SH3 domain is represented in Figure $4 \mathrm{C}$ and the interface of interaction between RAD51a and ABL1 tyrosine kinase domain is represented in Figure 4D. $A B L 1$ interaction with RAD51a guarantees a faithful DSBs repair and genomic stability, in a way that it helps to achieve a proper functioning of oncogene metabolism $[20,85]$. Moreover, it has been shown that RAD51a is regulated by tyrosine phosphorylation at residues 54 and 315 [86]. Here, we found a hot spot on Tyr 314 (Table 1), which may as well contribute to the interaction of ABL1 and RAD51a.

We found 4 conserved hot spot residues (Figure 5A) within the interaction interface of ABL1 SH3 and RA- 

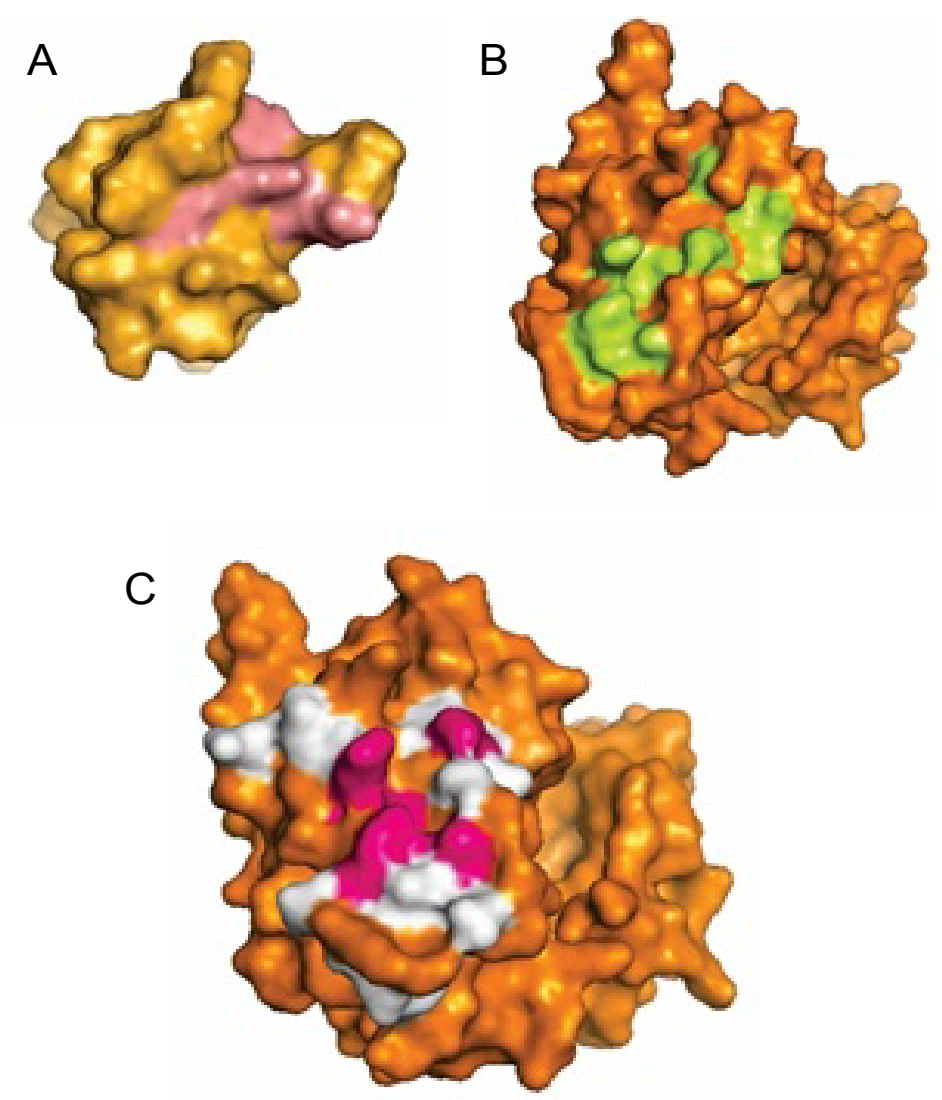

Figure 5: Hot spots prediction in ABL1 domains. A - The figure represents in pink the predicted hot spots on the $A B L 1$ SH3 domain (orange) when it interacts with RAD51a. B - The figure represents in pink the predicted hot spots on the ABL1 tyrosine kinase domain (orange) when it interacts with RAD51a. C - The figure shows highly polymorphic residues that overlaps hot spots (pink) or are present in the proximity of hot spots (white) in the ABL1 tyrosine kinase domain (orange).

D51a and 10 conserved hot spot residues (Figure 5B) within the interaction interface of $A B L 1$ tyrosine kinase and RAD51a (Table 4). Among those, 5 have been identified as polymorphic residues as Met 437 can be changed into lle, lle 443 into Thr, Tyr 456 into Cys, Glu 459 into Lys and Leu 451 as a synonymous mutation (Figure 5C).

\section{Concluding Remarks}

Cancer is a prevalent disease worldwide. RAD51a, PCNA, FANCD2 and ABL1 are potential therapeutic targets in cancer therapy. These proteins interact with a variety of molecules in order to maintain genomic stability. Protein-protein interactions (PPIs) are a key factor for a proper DNA metabolism and they regulate a wide range of biochemical pathways and processes. Here, we have shown the in silico interaction between RAD51a and the cancer-related proteins PCNA, FANCD2 and $A B L 1$ and we presented the most favorable free binding energy of hot spots important for those interactions. We believe that further studies may find small-targeted molecules with therapeutics properties that could modulate those interactions and increase our knowledge regarding the complex trait diseases such as cancer.

\section{References}

1. Kowalczykowski SC (2015) An Overview of the Molecular Mechanisms of Recombinational DNA Repair. Cold Spring Harb Perspect Biol 7.
2. Lehner K, Jinks-Robertson S (2014) Shared genetic pathways contribute to the tolerance of endogenous and low-dose exogenous DNA damage in yeast. Genetics 198: 519-530.

3. Soares JP, Silva AM, Fonseca S, Oliveira MM, Peixoto F, et al. (2015) How can age and lifestyle variables affect DNA damage, repair capacity and endogenous biomarkers of oxidative stress? Exp Gerontol 62: 45-52.

4. Ogrunc M, Di Micco R, Liontos M, Bombardelli L, Mione $M$, et al. (2014) Oncogene-induced reactive oxygen species fuel hyperproliferation and DNA damage response activation. Cell Death Differ 21: 998-1012.

5. Koulu L (2014) UV radiation, tanning and DNA damage]. Duodecim 130: 637-641.

6. Qiu GH (2015) Protection of the genome and central protein-coding sequences by non-coding DNA against DNA damage from radiation. Mutat Res Rev Mutat Res 764: 108-117.

7. Clewell RA, Sun $B$, Adeleye $Y$, Carmichael $P$, Efremenko A, et al. (2014) Profiling dose-dependent activation of p53mediated signaling pathways by chemicals with distinct mechanisms of DNA damage. Toxicol Sci 142: 56-73.

8. Wada K, Yoshida T, Takahashi N, Matsumoto K (2014) Effects of seven chemicals on DNA damage in the rat urinary bladder: a comet assay study. Mutat Res Genet Toxicol Environ Mutagen 769: 1-6.

9. Kianmehr M, Hajavi J, Gazeri J (2017) Assessment of DNA damage in blood lymphocytes of bakery workers by comet assay. Toxicol Ind Health 33: 726-735. 
10. Zhao Z, Xing X, Ou X, Liu X, Zhou R, et al. (2017) DNA damage levels in electronics workers in Southern China: $A$ micro-whole blood comet assay. Mutat Res 803-805: 1721.

11. Pater P, Seuntjens J, EI Naqa I, Bernal MA (2014) On the consistency of Monte Carlo track structure DNA damage simulations. Med Phys 41: 121708.

12. Scalise JR, Poças RCG, Caneloi TP, Lopes CO, Kanno DT, et al. (2016) DNA Damage Is a Potential Marker for TP53 Mutation in Colorectal Carcinogenesis. J Gastrointest Cancer 47: 409-416.

13. Galkin VE, Wu Y, Zhang XP, Qian X, He Y, et al. (2006) The Rad51/RadA N-terminal domain activates nucleoprotein filament ATPase activity. Structure 14: 983-992.

14. Liu J, Doty T, Gibson B, Heyer WD (2010) Human BRCA2 protein promotes RAD51 filament formation on RPAcovered single-stranded DNA. Nat Struct Mol Biol 17: 1260 1262.

15. Luo K, Li L, Li Y, Wu C, Yin Y, et al. (2016) A phosphorylationdeubiquitination cascade regulates the BRCA2-RAD51 axis in homologous recombination. Genes Dev 30: 2581-2595.

16. Chen X, Bosques L, Sung P, Kupfer GM (2016) A novel role for non-ubiquitinated FANCD2 in response to hydroxyureainduced DNA damage. Oncogene 35: 22-34.

17. Sato K, Shimomuki M, Katsuki Y, Takahashi D, Kobayashi W, et al. (2016) FANCI-FANCD2 stabilizes the RAD51DNA complex by binding RAD51 and protects the 5'-DNA end. Nucleic Acids Res 44: 10758-10771.

18. Chen G, Yuan SS, Liu W, Xu Y, Trujillo K, et al. (1999) Radiation-induced assembly of Rad51 and Rad52 recombination complex requires ATM and c-Abl. J Biol Chem 274: 12748-12752.

19. Popova M, Shimizu $H$, Yamamoto $K$, Lebechec $M$, Takahashi M, et al. (2009) Detection of c-Abl kinasepromoted phosphorylation of Rad51 by specific antibodies reveals that Y54 phosphorylation is dependent on that of Y315. FEBS Lett 583: 1867-1872.

20. Slupianek A, Dasgupta Y, Ren SY, Gurdek E, Donlin M, et al. (2011) Targeting RAD51 phosphotyrosine-315 to prevent unfaithful recombination repair in $B C R-A B L 1$ leukemia. Blood 118: 1062-1068.

21. GBD 2015 Disease and Injury Incidence and Prevalence Collaborators (2016) Global, regional, and national incidence, prevalence, and years lived with disability for 310 diseases and injuries, 1990-2015: a systematic analysis for the Global Burden of Disease Study 2015. Lancet 388: 1545-1602.

22. GBD 2015 Mortality and Causes of Death Collaborators (2016) Global, regional, and national life expectancy, allcause mortality, and cause-specific mortality for 249 causes of death, 1980-2015: a systematic analysis for the Global Burden of Disease Study 2015. Lancet 388: 1459-1544.

23. Gu L, Smith S, Li C, Hickey RJ, Stark JM, et al. (2014) A PCNA-derived cell permeable peptide selectively inhibits neuroblastoma cell growth. PLoS ONE 9: e94773.

24. Ma C, Wang Z, Nepal M, Hokutan K, Zhang J, et al (2018) DNA methylation at the vicinity of the proximal polyadenylation site in FANCD2 gene involves human malignancy. Cell Cycle 17: 2204-2206.

25. Sourbier C, Ricketts CJ, Matsumoto S, Crooks DR, Liao PJ, et al. (2014) Targeting ABL1-mediated oxidative stress adaptation in fumarate hydratase-deficient cancer. Cancer
Cell 26: 840-850.

26. Mason JM, Logan HL, Budke B, Wu M, Pawlowski M, et al. (2014) The RAD51-stimulatory compound RS-1 can exploit the RAD51 overexpression that exists in cancer cells and tumors. Cancer Res 74: 3546-3555.

27. Stürzbecher HW, Donzelmann B, Henning W, Knippschild $U$, Buchhop S (1996) p53 is linked directly to homologous recombination processes via RAD51/RecA protein interaction. EMBO J 15: 1992-2002.

28. Dai L, Zhao T, Bisteau X, Sun W, Prabhu N, et al. (2018) Modulation of Protein-Interaction States through the Cell Cycle. Cell 173: 1481-1494.e13.

29. Santucci M, Vignudelli T, Ferrari S, Mor M, Scalvini L, et al. (2015) The Hippo Pathway and YAP/TAZ-TEAD ProteinProtein Interaction as Targets for Regenerative Medicine and Cancer Treatment. J Med Chem 58: 4857-4873.

30. Huttlin EL, Ting L, Bruckner RJ, Gebreab F, Gygi MP, et al. (2015) The BioPlex Network: A Systematic Exploration of the Human Interactome. Cell 162: 425-440.

31. Vogelstein B, Papadopoulos N, Velculescu VE, Zhou S, Diaz LA, et al. (2013) Cancer genome landscapes. Science 339: 1546-1558.

32. Govindan R, Ding L, Griffith M, Subramanian J, Dees ND, et al. (2012) Genomic landscape of non-small cell lung cancer in smokers and never-smokers. Cell 150: 1121-1134.

33. Ghoorah AW, Devignes M-D, Smaïl-Tabbone M, Ritchie DW (2016) Classification and Exploration of 3D Protein Domain Interactions Using Kbdock. Methods Mol Biol 1415: 91-105.

34. Kozakov D, Hall DR, Xia B, Porter KA, Padhorny D, et al. (2017) The ClusPro web server for protein-protein docking. Nat Protoc 12: 255-278.

35. Darnell SJ, Page D, Mitchell JC (2007) An automated decision-tree approach to predicting protein interaction hot spots. Proteins 68: 813-823.

36. Darnell SJ, LeGault L, Mitchell JC (2008) KFC Server: interactive forecasting of protein interaction hot spots. Nucleic Acids Res 36: 265-269.

37. DeLano WL (2002) Unraveling hot spots in binding interfaces: progress and challenges. Curr Opin Struct Biol 12: $14-20$.

38. Wells JA, McClendon CL (2007) Reaching for high-hanging fruit in drug discovery at protein-protein interfaces. Nature 450: 1001-1009.

39. Zhong S, Macias AT, MacKerell AD (2007) Computational identification of inhibitors of protein-protein interactions. Curr Top Med Chem 7: 63-82.

40. Ni K, Zhou Y, Sun Y, Liu Y, Gu X, et al. (2014) Intrathecal injection of selected peptide Myr-RC-13 attenuates bone cancer pain by inhibiting KIF17 and NR2B expression. Pharmacol Biochem Behav 122: 228-233.

41. Lee E, Lee SJ, Koskimaki JE, Han Z, Pandey NB, et al. (2014) Inhibition of breast cancer growth and metastasis by a biomimetic peptide. Sci Rep 4: 7139.

42. Zhang T, Wu K, Ding C, Sun K, Guan Z, et al. (2015) Inhibiting bladder tumor growth with a cell penetrating R11 peptide derived from the p53 C-terminus. Oncotarget 6 : 37782-37791.

43. Peng SB, Zhang X, Paul D, Kays LM, Gough W, et al. (2015) Identification of LY2510924, a novel cyclic peptide CXCR4 antagonist that exhibits antitumor activities in solid 
tumor and breast cancer metastatic models. Mol Cancer Ther 14: 480-490.

44. Cao J, Wang R, Gao N, Li M, Tian X, et al. (2015) A7RC peptide modified paclitaxel liposomes dually target breast cancer. Biomater Sci 3: 1545-1554.

45. Galasko D, Bell J, Mancuso JY, Kupiec JW, Sabbagh MN, et al. (2014) Clinical trial of an inhibitor of RAGE-A $\beta$ interactions in Alzheimer disease. Neurology 82: 15361542.

46. Kanthasamy AG, Anantharam V, Zhang D, Latchoumycandane $\mathrm{C}$, Jin $\mathrm{H}$, et al. (2006) A novel peptide inhibitor targeted to caspase-3 cleavage site of a proapoptotic kinase protein kinase $\mathrm{C}$ delta (PKCdelta) protects against dopaminergic neuronal degeneration in Parkinson's disease models. Free Radic Biol Med 41: 1578-1589.

47. Gu B, Huang $Y Z$, He XP, Joshi RB, Jang $W$, et al (2015) A Peptide Uncoupling BDNF Receptor TrkB from Phospholipase Cy1 Prevents Epilepsy Induced by Status Epilepticus. Neuron 88: 484-491.

48. Yu Y, Deng YQ, Zou P, Wang Q, Dai Y, et al. (2017) A peptide-based viral inactivator inhibits Zika virus infection in pregnant mice and fetuses. Nat Commun 8: 15672.

49. Moldovan GL, Pfander B, Jentsch S (2007) PCNA, the maestro of the replication fork. Cell 129: 665-679.

50. Essers J, Theil AF, Baldeyron C, Cappellen WA van, Houtsmuller AB, et al. (2005) Nuclear Dynamics of PCNA in DNA Replication and Repair. Mol Cell Biol 25: 9350-9359.

51. Goellner EM, Smith CE, Campbell CS, Hombauer $H$ Desai A, et al. (2014) PCNA and Msh2-Msh6 activate an Mlh1-Pms1 endonuclease pathway required for Exo1independent mismatch repair. Mol Cell 55: 291-304.

52. Poot RA, Bozhenok L, van den Berg DLC, Steffensen S, Ferreira F, et al. (2004) The Williams syndrome transcription factor interacts with PCNA to target chromatin remodelling by ISWI to replication foci. Nat Cell Biol 6: 1236-1244.

53. Liang Z, Diamond M, Smith JA, Schnell M, Daniel R (2011) Proliferating cell nuclear antigen is required for loading of the SMCX/KMD5C histone demethylase onto chromatin. Epigenetics Chromatin 4: 18

54. Jones S, Thornton JM (1996) Principles of protein-protein interactions. Proc Natl Acad Sci USA 93: 13-20.

55. Jones S, Thornton JM (1997) Analysis of protein-protein interaction sites using surface patches. J Mol Biol 272: 121132

56. Garg P, Burgers PMJ (2005) DNA polymerases that propagate the eukaryotic DNA replication fork. Crit Rev Biochem Mol Biol 40: 115-128.

57. Solinger JA, Kiianitsa K, Heyer W-D (2002) Rad54, a Swi2/ Snf2-like recombinational repair protein, disassembles Rad51:dsDNA filaments. Mol Cell 10: 1175-1188.

58. Li X, Heyer WD (2009) RAD54 controls access to the invading 3 ' $-\mathrm{OH}$ end after RAD51-mediated DNA strand invasion in homologous recombination in Saccharomyces cerevisiae. Nucleic Acids Res 37: 638-646.

59. Ma X, Jin Q, Försti A, Hemminki K, Kumar R (2000) Single nucleotide polymorphism analyses of the human proliferating cell nuclear antigen (pCNA) and flap endonuclease (FEN1) genes. Int J Cancer 88: 938-942.

60. Zienolddiny S, Campa D, Lind H, Ryberg D, Skaug V, et al. (2006) Polymorphisms of DNA repair genes and risk of non-small cell lung cancer. Carcinogenesis 27: 560-567.

61. Garcia-Higuera I, Taniguchi T, Ganesan S, Meyn MS, Timmers C, et al. (2001) Interaction of the Fanconi anemia proteins and BRCA1 in a common pathway. Mol Cell 7: 249-262.

62. Lachaud C, Moreno A, Marchesi F, Toth R, Blow JJ, et al. (2016) Ubiquitinated Fancd2 recruits Fan1 to stalled replication forks to prevent genome instability. Science 351: 846-849.

63. Whitney M, Thayer M, Reifsteck C, Olson S, Smith L, et al. (1995) Microcell mediated chromosome transfer maps the Fanconi anaemia group $D$ gene to chromosome $3 p$. Nat Genet 11: 341-343.

64. Green AM, Kupfer GM (2009) Fanconi anemia. Hematol Oncol Clin North Am 23: 193-214.

65. Bagby GC, Alter BP (2006) Fanconi anemia. Semin Hematol 43: 147-156.

66. He M, Sun HG, Hao JY, Li YL, Yu JK, et al. (2013) RNA interference-mediated FANCF silencing sensitizes OVCAR3 ovarian cancer cells to adriamycin through increased adriamycin-induced apoptosis dependent on JNK activation. Oncol Rep 29: 1721-1729.

67. Oda Y, Hidaka M, Suzuki A (2017) Caffeine Has a Synergistic Anticancer Effect with Cisplatin via Inhibiting Fanconi Anemia Group D2 Protein Monoubiquitination in Hepatocellular Carcinoma Cells. Biol Pharm Bull 40: 20052009.

68. Wang GZ, Liu YQ, Cheng X, Zhou GB (2015) Celastrol induces proteasomal degradation of FANCD2 to sensitize lung cancer cells to DNA crosslinking agents. Cancer Sci 106: $902-908$.

69. Somyajit K, Subramanya S, Nagaraju G (2012) Distinct roles of $F A N C O / R A D 51 C$ protein in DNA damage signaling and repair: implications for Fanconi anemia and breast cancer susceptibility. J Biol Chem 287: 3366-3380.

70. Yao C, Du W, Chen H, Xiao S, Huang L, et al. (2015) Involvement of Fanconi anemia genes FANCD2 and FANCF in the molecular basis of drug resistance in leukemia. Mol Med Rep 11: 4605-4610.

71. Hussain S, Wilson JB, Medhurst AL, Hejna J, Witt E, et al. (2004) Direct interaction of FANCD2 with BRCA2 in DNA damage response pathways. Hum Mol Genet 13: 12411248.

72. Offman J, Gascoigne K, Bristow F, Macpherson P, Bignami $M$, et al. (2005) Repeated sequences in CASPASE-5 and FANCD2 but not NF1 are targets for mutation in microsatellite-unstable acute leukemia/myelodysplastic syndrome. Mol Cancer Res 3: 251-260.

73. Tang LL, Chen FY, Wang H, Hu XL, Dai X, et al. (2013) Haplotype analysis of eight genes of the monoubiquitinated FANCD2-DNA damage-repair pathway in breast cancer patients. Cancer Epidemiol 37: 311-317.

74. Levitus M, Rooimans MA, Steltenpool J, Cool NFC, Oostra AB, et al. (2004) Heterogeneity in Fanconi anemia: evidence for 2 new genetic subtypes. Blood 103: 2498-2503.

75. Vazharova R, Vragaleva S, Dimitrova V, Ivanov S, Balabanski L, et al. (2016) Novel Hypomorphic Mutation in FANCD2 Gene Observed in a Fetus with Multiple Congenital Anomalies. Case Rep Obstet Gynecol 2016: 1462818

76. Radha V, Nambirajan S, Swarup G (1996) Association of Lyn tyrosine kinase with the nuclear matrix and cell-cycle- 
dependent changes in matrix-associated tyrosine kinase activity. Eur J Biochem 236: 352-359.

77. Manning G, Plowman GD, Hunter T, Sudarsanam S (2002) Evolution of protein kinase signaling from yeast to man. Trends Biochem Sci 27: 514-520.

78. Pawson T, Schlessingert J (1993) SH2 and SH3 domains. Curr Biol 3: 434-442.

79. Whisstock JC, Lesk AM (1999) SH3 domains in prokaryotes. Trends Biochem Sci 24: 132-133.

80. Kohda D, Hatanaka H, Odaka M, Mandiyan V, Ullrich A, et al. (1993) Solution structure of the SH3 domain of phospholipase C-gamma. Cell 72: 953-960.

81. Manning G, Whyte DB, Martinez R, Hunter T, Sudarsanam $S$ (2002) The protein kinase complement of the human genome. Science 298: 1912-1934.

82. Li B, Liu Y, Uno T, Gray N (2004) Creating chemical diversity to target protein kinases. Comb Chem High Throughput Screen 7: 453-472.
83. Schaller MD, Borgman CA, Cobb BS, Vines RR, Reynolds $A B$, et al. (1992) pp125FAK a structurally distinctive proteintyrosine kinase associated with focal adhesions. Proc Natl Acad Sci USA 89: 5192-5196.

84. Yuan ZM, Huang $\mathrm{Y}$, Ishiko $\mathrm{T}$, Nakada $\mathrm{S}$, Utsugisawa $\mathrm{T}$, et al. (1998) Regulation of Rad51 Function by c-Abl in Response to DNA Damage. J Biol Chem 273: 3799-3802.

85. Soverini S, Martinelli G, Rosti G, Bassi S, Amabile M, et al. (2005) ABL mutations in late chronic phase chronic myeloid leukemia patients with up-front cytogenetic resistance to imatinib are associated with a greater likelihood of progression to blast crisis and shorter survival: a study by the GIMEMA Working Party on Chronic Myeloid Leukemia. J Clin Oncol 23: 4100-4109.

86. Subramanyam S, Ismail M, Bhattacharya I, Spies M (2016) Tyrosine phosphorylation stimulates activity of human RAD51 recombinase through altered nucleoprotein filament dynamics. Proc Natl Acad Sci U S A 113: E6045-6054. 